\title{
Serum Concentration of Copper, Zinc, Iron, and Cobalt and the Copper/Zinc Ratio in Horses with Equine Herpesvirus-1
}

\author{
İbrahim Yörük • Yeter Deger • Handan Mert • \\ Nihat Mert
}

Published online: 15 September 2007

(C) Humana Press Inc. 2007

The revised list of contributors is as above: İbrahim Yörük, Yeter Deger, Handan Mert, and Nihat Mert. V. Ataseven was mistakenly listed as an author.

The online version of the original article can be found at http://dx.doi.org/10.1007/s12011-007-0023-y.

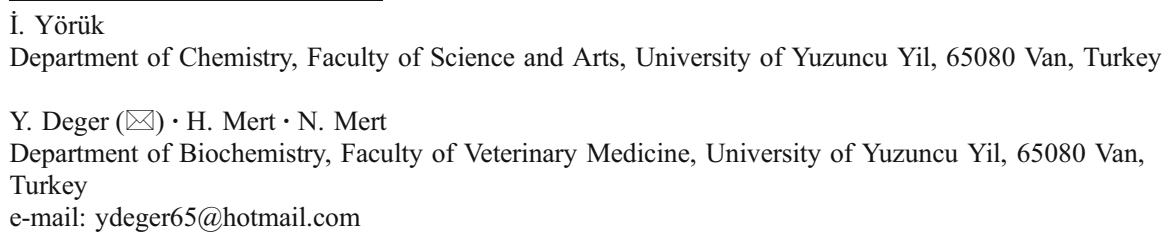

